\title{
The Cataloger and the Archivist Should Be Friends: or, Herding vs. Milking Special Collections
}

Author's Note: This essay is a kind of opinion piece rather than a scientifically based set of conclusions about rare book catalogers and technical services archivists. Its statements are based on experience and observation but not on a detailed survey of all the practitioners of rare book cataloging or archival processing in the United States. There are doubtless exceptions to its generalizations.

At the opening of Act II of the musical Oklahoma!, Old Man Carne sings:

The farmer and the cowman should be friends,

Oh, the farmer and the cowman should be friends,

One man likes to push a plough,

The other likes to chase a cow,

But that's no reason why they cain't be friends.

Territory folks should stick together,

Territory folks should all be pals ...

I would say that technical services archivists and rare book catalogers play roles as different as those of the farmer and the cowman, even though both work in the territory of special collections. They do their work using almost opposite mental processes, based on fundamental differences in the nature of the materials they work with and the standards for processing those materials. Technical processing even tends to attract different personality types in archives vs. rare book collections. Nonetheless, the dividing lines between these professions are less pronounced than they once were, and they will probably continue to fade in the future.

\section{Different Mental Worlds}

The differences in mentality between technical services archivists and rare book catalogers come partly from differences in the materials they work with and in the ways they approach them. These differences show up in their respective cataloging

1. Richard Rodgers and Oscar Hammerstein II, “The Farmer and the Cowman," in Oklahoma!: A Musical Play, vocal score (New York: Williamson Music, 1943), 142-43. 
frameworks, ISAD $(G)$ (General International Standard Archival Description) and ISBD (International Standard Bibliographic Description).

ISAD $(G)$, the framework on which Describing Archives: A Content Standard (DACS) ${ }^{2}$ is based, focuses on description at the collection level. This framework calls for the technical services archivist to summarize the overall characteristics of a collection; to hit the highlights, usually not concerned with minute detail or with extensive transcription; and, often, to create a description with multiple levels. An EAD finding aid, for instance, begins with a description of the collection as a whole, followed by a description of its series, ${ }^{3}$ which leads to a container list with a description at the box, folder, or item level. ISAD $(G)$ contains a number of elements that would seem alien to a rare book cataloger: an entire section on multilevel description; another entire section called the "Context Area," including rules that call for notes describing the collection's administrative or biographical history, its archival (custodial) history, and immediate source of acquisition or transfer; and two whole sections concerning the management and use of the collection. The first of these two management/ use sections, the "Content and Structure Area," calls for notes on the collection's scope and content; appraisal, destruction, and scheduling information; accruals; and systems of arrangement. The second of these sections, the "Conditions of Access and Use Area," calls for notes on the conditions governing access or reproduction; the language and script(s) of the material; and the collection's finding aid. ${ }^{4}$ All of these notes add up to a lot of information in the archival catalog record (and/or the finding aid) about the collection's context, history, management, and use.

ISBD, on the other hand, the framework on which AACR2 and DCRM $(B)^{5}$ are based, focuses on describing not a collection but an individual work. It calls for the cataloger to precisely identify a manifestation and distinguish it from other manifestations of the same work. ${ }^{6}$ This intellectual process of drawing distinctions is

2. Society of American Archivists, Describing Archives: A Content Standard (Chicago: SAA, 2004), the American cataloging standard for manuscripts and archives.

3. EAD stands for Encoded Archival Description, a metadata framework that allows one to post an archival finding aid online. For more information, see the Society of American Archivists' EAD Roundtable, "What Is EAD?" at www.archivists.org/saagroups/ead/aboutEAD.html [Accessed 30 August 2010]. "Series" is used here in the archival sense as a subset of a collection.

4. International Council on Archives, $\operatorname{ISAD}(G)$ : General International Standard Archival Description, 2nd ed. (Ottawa, Ont.: ICA, 2000), www.icacds.org.uk/eng/ISAD(G).pdf [Accessed 16 August 2010].

5. Anglo-American Cataloguing Rules, 2nd ed., rev. (Chicago: American Library Association, 1979; most recent full printed update 2005); Bibliographic Standards Committee, Rare Books and Manuscripts Section, Association of College and Research Libraries, Descriptive Cataloging of Rare Materials (Books) (Washington, D.C.: Cataloging Distribution Service, Library of Congress, 2007), the American cataloging standard for rare books.

6. The term "manifestation" is used here in keeping with the terminology of the IFLA Study Group on the Functional Requirements for Bibliographic Records, Functional Requirements for Bibliographic Records: Final Report (Munich: K.G. Saur, 1998; as amended through February 2009: www.ifla.org/files/ cataloguing/frbr/frbr_2008.pdf [Accessed 1 September 2010]). An example of a manifestation would be a particular edition of a book. 
virtually the opposite of the summarizing done by archivists. ISBD emphasizes transcription and focuses on creating a definitive description of the work at a single level. It includes sections on the title and statement of responsibility area; the edition area; the publication, production, and distribution area; the physical description area; the series area; and the note area. Multilevel description is covered in an appendix; but, as its placement suggests, it is used only rarely and under special circumstances. ${ }^{7}$ The title and publication/production/distribution areas in particular give detailed instructions on transcription: what to transcribe, how to transcribe it, where to put it, when and how to abridge it, and so on.

From an archivist's point of view, ISBD is notable for what it does not include. There is no section on context and none on the management or use of the work. Instead, the work is treated as a largely self-sufficient entity. There is room for notes on its history, provenance, and other contextual aspects, of course, but these are optional, not mandatory.

As this brief overview suggests, the differences between ISAD(G) and ISBD are striking. The two standards reflect differing views of the importance of transcription, the importance of context, the importance of the title, and standardization vs. flexibility; they even reflect differing concepts of the creator or author. In ISBD, the author is the person or body responsible for the intellectual or artistic content of the work; in $\operatorname{ISAD}(\mathrm{G})$, the creator may be the author of the material, but he/she/it could also be the person or body who created, assembled, or maintained the collection.

Altogether, archival description is much more freewheeling than book cataloging. The rare book cataloger not only has more detailed rules to follow, but the cataloger also knows that his or her catalog records will be scrutinized by rare book catalogers at other institutions who are looking for a record to use to catalog their copies of the same book. Substandard catalog records can damage the cataloging institution's national reputation, at least within the cataloging community. For archivists, by contrast, the descriptive standard is much less detailed and more flexible; and, because the archivist is describing a unique collection, the description won't be reused. As a result, archivists have more independence than book catalogers in how they describe the material and are under less pressure to carefully follow all the rules.

\section{Different Material Worlds, Different Vocabularies}

Archivists and rare book catalogers also tend to occupy different worlds in terms of the material they work with. On the level of broad generalizations, one may ven-

7. ISBD Review Group, International Federation of Library Associations and Institutions, International Standard Bibliographic Description (ISBD), preliminary consolidated ed. (Munich: K.G. Saur, 2007). 
ture that American archives tend to include a vast range of types of material, and a broad range of subjects; yet the geographical, chronological, and linguistic range of their collections may be narrow, focused mainly on life in the United States from the 19th century onward. (One can see this focus in DACS, where all of the examples are taken from modern materials in English.) Finally, American archives tend to include more material documenting "ordinary" lives than is found in rare book collections.

Rare print material collections found in American libraries, on the other hand (to continue the large generalizations), tend to include a relatively narrow range of types of material, usually consisting of books, pamphlets, broadsides, and serials. But they cover a broad range of subjects and have a broader geographical, chronological, and linguistic range than American archival collections typically possess, often ranging over Europe and Asia as well as the Americas and covering several centuries. Rare book collections also are frequently more highbrow in focus than archives, with less emphasis on the lives of "ordinary" people.

The thesauri used by rare book catalogers and technical services archivists reflect the differences in the materials they process. In addition to LCSH (the Library of Congress Subject Headings), rare book catalogers commonly use the RBMS Controlled Vocabularies ${ }^{8}$ and MARC relator terms; ${ }^{9}$ and while the relator terms range over materials in multiple formats, the Controlled Vocabularies focus on printed material. Archivists, on the other hand, may supplement LCSH with the Art and Architecture Thesaurus (AAT) ${ }^{10}$ and Thesaurus for Graphic Materials II (TGM II), ${ }^{11}$ which range over many kinds of artwork and realia in addition to manuscripts, in keeping with the broad range of materials often found in archival collections.

\section{Historical Cataloging Conditions}

Technological and administrative factors have further separated the mental worlds of technical services archivists and rare book catalogers. At those institutions that cataloged in RLIN, for example, ${ }^{12}$ before format integration occurred in the mid-

8. Bibliographic Standards Committee, Rare Books and Manuscripts Section, Association of College and Research Libraries, RBMS Controlled Vocabularies. Available online at http://rbms.info/committees/ bibliographic_standards/controlled_vocabularies/index.shtml [Accessed 16 August 2010].

9. Network Development \& MARC Standards Office, Library of Congress, MARC Code List for Relators. Available online at www.loc.gov/marc/relators/relaterm.html [Accessed 16 August 2010]

10. Getty Vocabulary Program, Art and Architecture Thesaurus. Available online at www.getty.edu/ research/conducting_research/vocabularies/aat/ [Accessed 16 August 2010].

11. Prints and Photographs Division, Library of Congress, Thesaurus for Graphic Materials II: Genre \& Physical Characteristic Terms. Available online at www.loc.gov/rr/print/tgm2/ [Accessed 16 August 2010].

12. RLIN, the Research Libraries Information Network, was a utility analogous to OCLC but created specifically to meet the needs of research libraries. 
$1990 \mathrm{~s},{ }^{13}$ for about 15 years each format had its own separate file in the database. The result was that book catalogers and archivists could each work for years without ever seeing a catalog record in the other's format.

Before the online catalog and budget cuts caused consolidation, rare book and archives departments were also usually physically and administratively separate (as they still are at many institutions), and they had very separate cultures. Traces of their formerly separate worlds remain today: bound manuscripts that were cataloged as books decades ago because they were in the rare book department; periodicals or books that were cataloged as archival collections decades ago because they were in the archives. For the denizens of these departments, cataloging everything in the same few formats was not mere laziness. It saved them a good deal of time to describe materials in terms of the formats they knew by heart, rather than to stop and learn the cataloging rules for an unfamiliar format that they might encounter only occasionally. They had little reason to consider the problems this format-crossing might create for users trying to narrow down a search by format in an integrated online public catalog, because at the time few libraries had an online public catalog.

As they have done from the beginning of their professions in the United States, today archivists and rare book catalogers also go through differing professional education processes, and these, too, give them differing mental frameworks. Looking through issues of professional journals such as American Archivist, Archival Outlook, and $R B M$, one can see that the American archives profession puts more emphasis on democratic values and the lives of "ordinary" people than rare book librarianship does. While in recent years rare book librarians have broadened the scope of their collecting to include much more popular culture than in decades past, their profession still does not have the same democratic focus as the archives community.

An additional difference that shapes the attitudes of librarians and archivists is this, to put it bluntly: a rare book is a lot easier to lose or to steal than an archival box is. Also, an archival collection usually does not look valuable (outwardly, it's usually a group of boxes), while a rare book frequently does look valuable (outwardly, it's an old and possibly gorgeous binding). This difference in vulnerability to theft makes a big difference in catalogers' vs. archivists' attitudes toward the material. Rare book catalogers tend to be much more on high alert than archivists are about proper handling, security, and keeping careful track of individual items.

13. OCLC documentation suggests that format integration went into effect in February 1995. See OCLC's “Guidelines for National Level Enhance Participants." Available online at www.oclc.org/support/documentation/worldcat/ records/enhanceguidelines/ [Accessed 30 August 2010]. 
The lack of item-level description in archival catalog records and finding aids can give a rare book librarian hives. Accustomed to dealing with the individual book, she is apt to wonder, "How can we possibly keep track of our collections without cataloging every item?" For their part, archivists have had to live with this situation for many years, and they are used to it. If dozens or hundreds of boxes' worth of material are coming in every year, with minimal staff to process them, item-level description is out of the question.

\section{Different Professions, Different People}

With all of these differences in their materials, training, cataloging standards, and environments, it's not surprising that the professions of archival technical services and rare book cataloging - the work of summarizing and that of differentiatingoften attract different personality types. This can cause occasional tensions. To a rare book cataloger, an archivist can seem too free and easy, insufficiently meticulous, and a bit disrespectful of the cataloging rules. To an archivist, on the other hand, a rare book cataloger can seem uptight, pedantic, fussy, and authoritarian. The cataloger wishes the archivist would reread the rules and take them to heart. The archivist wishes the cataloger would quit obsessing over details, when another dozen or hundred boxes are coming in next week.

\section{Forces for Convergence}

Despite all these differences between them, though, powerful forces are now bringing archivists and rare book catalogers closer together. Budget pressures are encouraging rare book catalogers to do more collection-level cataloging of print materials, which forces them to think more like archivists. Meanwhile, the proliferation of metadata standards is exposing both librarians and archivists to multiple ways of conceptualizing description. In particular, digitization projects and their metadata requirements are introducing many special collections staff to new ways of describing material.

Archivists have an advantage here in that they are used to being flexible about how they describe their collections. For decades, every time they have processed a collection, they have described it according to two different conceptual frameworks: the collection-level catalog record and the finding aid. Their cataloging standard is also more flexible and less detailed than AACR2, and hence easier to adapt to other contexts.

Of course, there have been some similarities in the work of rare book catalogers and archivists all along. Both deal not with the mass-produced mainstream of library materials but (often) with the weird exceptions. Both have to have a tolerance for ambiguity and quirkiness: an archivist may have to a catalog a manuscript 
with no title, no identified creator, and no discernible century; or a cataloger may have to describe a book sewn together by someone who was illiterate and possibly drunk. The print items we have encountered at Cornell include artists' books shaped like an apple and a walnut, respectively; a book consisting of paper dolls; and Spiderman comic books. The archival collections we have processed include Tshirts, wedding socks, painted dolls, locks of hair, and early 20th-century vibrators. Whether in a rare book or an archival context, special collections cataloging is not for sissies.

Both rare book catalogers and archivists also apply their knowledge of the work's (or collection's) historical context to make sense out of it, usually in the absence of contextual information on or in the items themselves. Both have to balance a concern for historical significance and security considerations (which encourage cataloging depth) against the limitations of time and funding and the need to minimize the backlog (which encourage speed). Both catalogers and archivists also have to bear multiple types of users in mind: advanced scholars, curators, donors, rare book dealers, librarians at other institutions, students, casual visitors, and the general public.

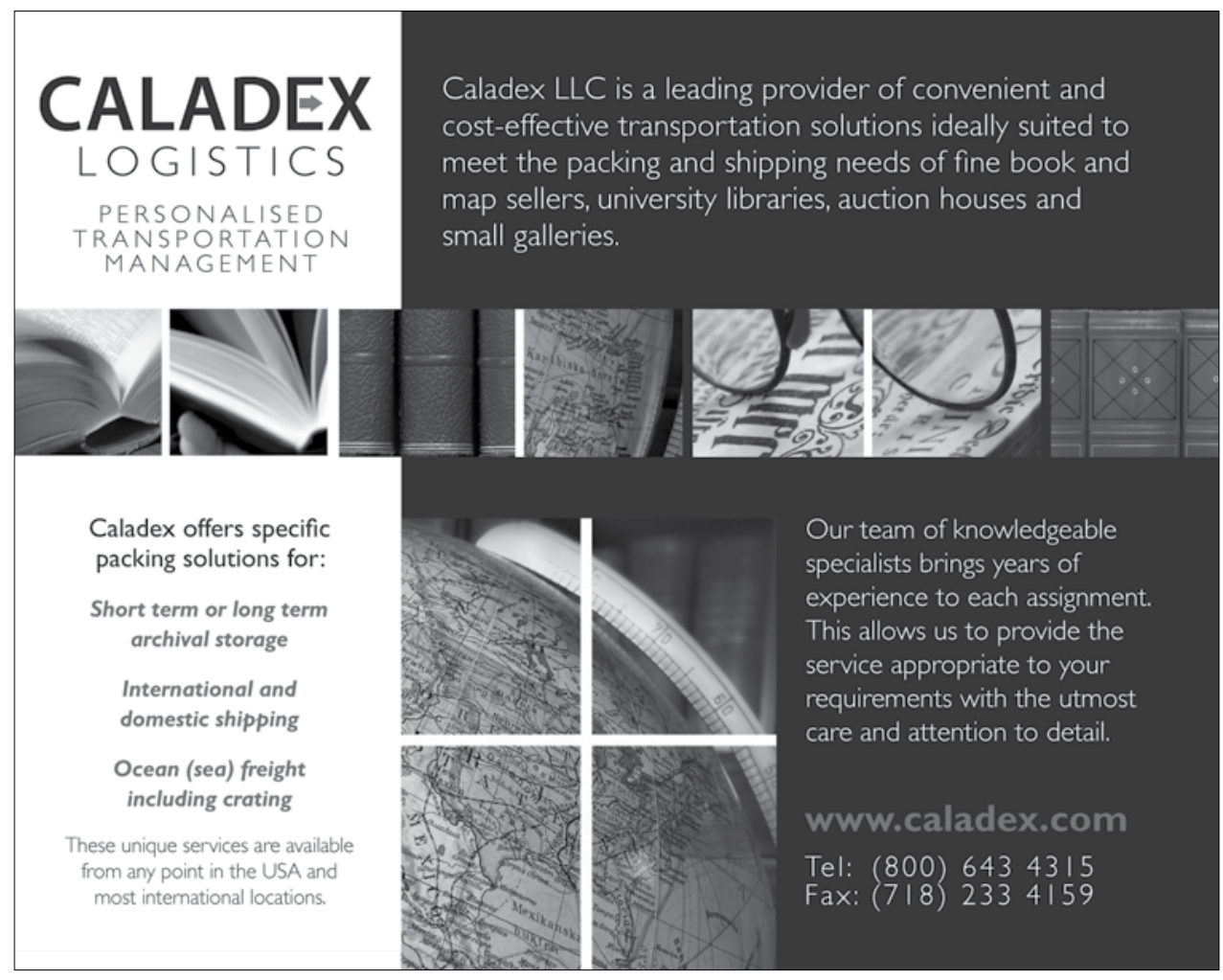




\section{How to Communicate Better?}

In these days of proliferating formats and increased emphasis on popular culture materials, it would be helpful for technical services staff in special collections to consult each other more across format (and professional) boundaries. They may find useful meeting grounds in in-between types of material, such as collections of print materials to be described at the collection level, or book-like bound manuscripts. These intermediate materials create opportunities for rare book catalogers and archivists to collaborate. Curators, too, can benefit from greater exposure to how the other half lives within their special collections department. It may be that the collection of 10,000 items that they were bracing themselves for, resigned to waiting years for it to be processed item by item, is in fact an excellent candidate for a collection-level record and a finding aid, which can be done in a fraction of the time. Conversely, a collection of manuscripts that will in fact be used item by item may benefit from item-level description. There is more than one way to catalog, even though many of us "grew up" in the profession using only one.

Digitization projects and other metadata enterprises provide another opportunity for catalogers and archivists to collaborate and to learn together. Archivists are in the better position to move into the future, I believe, because their existing cataloging standard (DACS) is a content standard, applicable across a couple of different document type definitions: MARC and EAD. Rare book and mainstream library catalogers can learn from archivists on this score.

Cataloging cosmopolitanism is useful for our profession in the here and now as well as for the future. Like gender and sexual orientation, format can in fact be ambiguous, more of a spectrum than a series of sharply divided categories. Library materials have their hermaphrodites, transvestites, and transgendered individuals, too-materials that really could be described in terms of a couple of different formats. A photograph album with extensive manuscript captions is an example: is it a visual resource, a bound manuscript, or mixed material? Instead of applying the Procrustean bed approach and distorting the description to fit his or her cataloging preferences, a cataloger familiar with multiple approaches to description can choose the one that best fits the material and its likely uses.

\section{The Future: Cowman Farmers?}

Given that libraries and archives appear to be in for continuing budget reductions for the foreseeable future, shrinking staffing may generate demand for people who can serve as both technical services archivists and rare book catalogers. The major obstacles to this convergence between librarianship and archival practice are our current specialization of cataloging skills, long-standing customs in administrative organization, and differing cultures. As we have noted, technical services archivists and rare 
book catalogers commonly use almost opposite mental processes. Not everyone who is good at summarizing is also good at drawing distinctions, and vice versa. On the other hand, in some current library positions the same person is called on to serve as both a curator and a cataloger, or both a cataloger and a public services librarian. If a single person can reasonably be asked to play such different roles, it is not unreasonable to ask someone to catalog both rare books and archival collections.

For some of us who "grew up" in the profession with rare book cataloging and archival description in very separate departments, it may seem strange to contemplate the possible merging of these two professions into one. But we should not underestimate the power of budget reductions to drive everything before them. In response to such reductions, some institutions have already merged their archives with their rare book departments, bringing archivists and rare book librarians into constant contact and requiring them to learn much about each other's work. ${ }^{14}$ The University of Denver's Penrose Library has actually consolidated its cataloging and archival processing departments into a single unit, where staff members collaborate to process materials in all formats. ${ }^{15}$ One could argue that at sites like this one, the dividing line between our professions is already fading. In short, my fellow farmers, it's time we bought ourselves cowboy hats.

14. Recent examples of archives merged with libraries include the Division of Rare and Manuscript Collections at Cornell University Library (formed by merger in 1992) and the Library and Archives Canada (formed by merger in 2004). The director of the latter institution has the title Librarian and Archivist of Canada.

15. Gregory C. Colati, Katherine M. Crowe, and Elizabeth S. Meagher, "Better, Faster, Stronger: Integrating Archives Processing and Technical Services," Library Resources \& Technical Services 53.4 (Oct. 2009): 261-70.

\section{In the Hurricane's Eye: Challenges of collecting in the 21si century}

In the last several years special collections and archives have assumed a new and more prominent role within our larger host institutions as well as in the wider library community. Once perceived as peripheral to core library services, our collections are now viewed as central. Despite-or perhaps because of-this centrality, we face a perfect storm of increasing needs in a time of decreasing support. How can we keep building and providing effective access to collections that will remain central in the future, fulfilling our obligation to provide stewardship of the cultural record? Join us at the 52nd Annual RBMS Preconference and find out! See www.rbms.info for details.

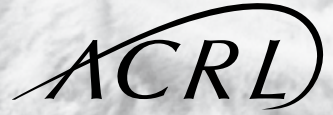

Association of College \& Research Libraries A Division of the Ameican binassociton

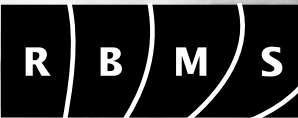

52nd Annual RBMS Preconference Baton Rouge, LA June 21- 24, 2011 